\title{
Sustainable Green Space System in High-density Cities__ Based on the GI Theory
}

\author{
Xi Xiao,a , Min $\mathrm{Li}^{* 1,2, ~ b}$, Lin Yuanº \\ ${ }^{1}$ Faculty of architecture and urban planning, \\ Chongqing University, \\ Chongqing, China. \\ ${ }^{2}$ College of forestry, South China Agricultural University, \\ Guangzhou, China. \\ a118178347@qq.com, bgdlimin@qq.com, c314070375@qq.com
}

\begin{abstract}
Green infrastructure (GI) as a way of comprehensive spatial planning based on the conservation and management of land resources, against the spread of environmental, social and economic impact caused by urban phenomenon, provides strategic solution to ease the high-density urban land use, economic and ecological development, culture protection and urban expansion. This paper puts forward some guide for urban green space system planning of high density urban development through the review dynamic development of GI theory application in foreign cities, namely, to carry out forward-looking initiative project of sustainable planning, construct multi-functional and flexibly connected green space system and dispersed green space and use GI benefit assessment means to optimize related development policy.
\end{abstract}

Keywords-high-density city; green space system; construction principles; sustainable development; GI (Green infrastructure)

\section{INTRODUCTION}

It is indicated in the latest data statistics of the United Nations Fund for Population Activities that more than half of global population lived in the cities covering nearly $3 \%$ of the land area on the earth in 2010. In the year of 2011, China's urbanization rate also exceeded $50 \%$ and was still in the rapid development interval of the Northam Curve, which manifests a more obvious tendency of high-density urban population in the future. In high-density cities, the green space is scarce and scattered, the urban ecological environment is poor, and the quality of residents' living environment is worrying. Therefore, exploring the way to plan and construct green space system for high-density cities are conducive to guaranteeing the ecological infrastructure of the high-density development of cities and creating a livable habitat as far as possible.

As a kind of comprehensive space planning method based on the conservation and management of land resources for alleviating the environmental, social and economic impact caused by urban sprawl, green infrastructure may put forward a strategic solution to relieving the contradictions of urban land use, economic and ecological development, cultural protection and urban expansion in high-density cities. In May 1999, in the report
Towards a Sustainable America - Advancing Prosperity, Opportunity, and a Healthy Environment for $21^{\text {st }}$ Century held by President's Council on Sustainable Development, GI was identified as one of the important strategies for the sustainable development of communities. [1] After that, the concept was spread to Western Europe. Although Western Europe has no large-scale urban sprawl which is similar to that in America, the problems of ecological protection, climate change and reconstruction of old cities in the process of urbanization are prominent. For this reason, Western Europe's GI places extra emphasis on the quality of the green space in urban environment, the maintenance of the multiple links between biodiversity and wildlife habitat [3], as well as the role of green infrastructure in preserving urban landscape [4], promoting public health [5-6] and reducing urban crime, and it has conducted a series of planning practice.

High-density cities are confronted with multiple complicated sustainable contradictions such as land use, economic and ecological development, cultural protection and urban expansion. [7] Planning and constructing green space in high-density cities has become a topic we should seriously study.

\section{DEFINING A GI THEORY IN DIFFERENT SCALE}

The concept of GI which is widely recognized at present was proposed by Benedict Mark and McMahon Edward from the Conservation Fund, "Green infrastructure is our nation's natural life support system An interconnected network of waterways, wetlands, woodlands, wildlife habitats, and other natural areas; greenways, parks and other conservation lands; working farms, ranches and forests; and wilderness and other open spaces that support native species, maintain natural ecological processes, sustain air and water resources and contribute to the health and quality of life for America's communities and people.” [8] GI contains the contents at two levels. The first level mainly aims at urban scale and the second level mainly aims at regional scale, but they both uphold the idea of "protection before development". However, in some European theories, GI is divided into four categories according to spatial scale, namely transnational, national, city-region, and urban. [9] In this 
paper, the research object is mainly the GI planning at the urban scale.

At the scale of geographic regions, GI provides necessary service functions of ecological system. At the urban scale, GI shapes the open space system, offering the guidance of smart planning. In the research specific to urban scale, a definition of urban green infrastructure (UGI for short)was given, which refers to "all the natural, semi-natural and artificial life support network systems, ecological or low-impact, inside, outside or among cities, which can provide multiple services and meanwhile promote the quality of humans and their living environment.” [10]

The study on the guiding principles, planning strategy and practice contents of GI in high-density cities and general cities indicates that the essence of GI is the same in different kinds of cities, and the following three aspects are emphasized: GI is natural life support system $[1,8]$; the connectivity among GI's various components is very important [8,9]; and GI serves as an important strategy for sustainable urban development $[3,5,8]$.

At present, the GI-related urban research cases are mainly in Europe and America, and the problems they are faced with are largely caused by urban sprawl, while high-density cities (such as Tokyo, Singapore, Hong Kong, et al.) are mainly confronted with the development problems and environmental problems brought by the high density of population and habitat. Therefore, they have many differences in the open space management principles and the relevant legal policies. It is necessary to summarize and explore the green space components and planning guidelines of high-density cities by borrowing the principles of general cities.

\section{GI'S COMPONENTS IN URBAN CONSTRUCTION}

With regard to the GI at the regional scale, it is usually classified according to "Hub-Link-Sites" [8]. High-density cities shift the focus of GI from regional scale to urban scale to face the existing urban structure and urban life for the purpose of finding a way to achieve a harmonious development between cities and natural ecosystem. The Open Space 2100 Seattle gathers more than 400 people from all walks of life to conduct the 2025 and 2100 Seattle GI Life Network Seminar. The ideas of participants are integrated systematically to extract five interconnected network systems [10-12], namely Habitat, Socio-economic and Open Space Access, Water, Transportation, and Energy. These five network systems are closely integrated inside cities and linked with the greenways and state parks outside cities, and connect the green open space to be a whole.

According to the research results of Carol Kambites, et al. [13-14], GI can be divided into 19 types on the basis of the provided functions to accord with and supplement the five systems, such as adding the contents of education and employment, history and context. This GI classification system provides the standard for the following visualized analysis, thus guiding the GI planning and construction of high-density cities.

\section{CONSTRUCTION PRINCIPLES OF GREEN SPACE SYSTEM FOR HIGH-DENSITY CITIES}

This paper selects three types of cities to conduct comparative study on the GI, trying to put forward the construction principles of green space system in high-density cities:

1) The American cities which first proposed the GI theory and applied, such as Seattle; [10-11]

2) The European cities which adjust, apply and popularize the GI theory according to local conditions, such as London (including GRaBS research, research on Northwest Region, and East London Green Grid Framework) [22-23];

3) The Asian countries with prominent development contradictions in high-density cities, such as Tokyo, Singapore, Hong Kong, et al. The planning method formed by such countries by applying the GI theory is of significant reference value. [7, 17-19]

\section{A. Forward-looking Strategies for Green Space Planning}

The high-density urban expansion has generated landscape fragmentation and passive land use. [8]Using the GI theory to evaluate urban vacant lot and guide land-use planning can change the originally passively growing land to the ecological "green infrastructure". Bowman and Pagano [15] perform an analysis in a report that, urban vacant lot includes bare land, the agricultural land in the marginal area of cities, wasteland, recently-leveled land, derelict land, the land of abandoned buildings and structures, and brown field. On the basis of such statistics, we can classify and choose the categories of land that may exist in high-density cities, and mark them with certain visual signs on the satellite map and site photo. Make judgment, selection and land replacement according to the different characteristics in high-density cities. [16]

Constructing GI by transforming vacant lot is an advanced international practice at present. For instance, New York transforms the vacant lot into greenways, bicycle paths, parks and the plantations which can provide income for poor people. [13] Seattle intends to conduct 25 years' and 100 years' planning to build a sustainable "beautiful city". [11] As a high-density "garden city", Singapore's construction of its national greenway network also first evaluates the underutilized areas and the uneconomic land to win the governmental support, and obtains the approval of relevant land management departments, so as to enhance the practicability of greenway planning [17]. Just like New York and Singapore, we can also evaluate the passive, underutilized land in high-density cities, conduct the GI planning by means of public participation and software analysis, emphasize the active, systematic, integral, multi-functional, multiply-controlled and multi-scale development pattern, 
and avoid the scattered, site-scale and single-purposed disorderly development in the past.

Since the block scale in high-density cities is small, it is necessary to follow the principle of "not detesting small land" when judging the vacant lot. Using both satellite remote sensing image and site survey to judge landscape elements subtly would be helpful to obtain objective results. The "Tokyo 2050 - Fiber City" [18,19] exactly adopts this way. It proposes to construct the 4-level green network of Green Finger, Green Partition, Green Cyber and Urban Wrinkle. Among that, Green Partition is a highly-connective "capillary" greenway designed for decentralized communities. Just like the blood capillary of human body is mutually connected with main arteries and veins, it is not only self-connected but connected with the large green space and greenway network at the regional scale such as schools and parks, and it also has the function of obstructing disasters in high-density blocks [18]. High-density cities should adopt this microscopic research method to conduct a comprehensive judgment and analysis of the idle urban land and make a forward-looking plan for green space system.

\section{B. Distributed Green Space with Flexibly-connected Layout}

A Guide to Green Infrastructure for Canadian Municipalities puts forward that the centralized, different infrastructure manufacturers and facilities will be replaced by various small-scale, distributed infrastructure systems in service areas. In the areas of renewable resources, distributed patterns are more advantageous. [20] The distributed energy system can gather thermal energy, rubbish or the methane of sewage disposal facilities from many sources, and the steam pump connected with underground pipeline or water body, the solar water heater on the roof, and the thermal energy generated in the production process of various factories are interconnected through regional heating supply system.In addition to energy, New York City divides the urban stormwater management into surface, roof and composite system according to the low impact theory in A Guide to the Design and Construction of Stormwater Management System formulated in 2012. The dispersed, small-scale and diversified low-impact technology can effectively control the pollution caused by the pollutants brought by rain wash to the receiving waters. [21] In high-density cities, the distributed green space system can utilize the space which is more fragmentary to improve GI's ecological efficiency.

Based on the research of urban GI planning, roads and water can be used to link the open space and weave a green network. Considering the complicated urban conditions and scarce land resources in high-density cities, it is even more necessary to emphasize their multi-functional and flexibility on the basis of connection, such as transforming street space into the streets with multiple functions of traffic evacuation, water purification, ecological stream corridor, and entertainment. [17] At the same time, the "fiber green corridor" which is similar to rainwater garden can also be established to link distributed green space in communities. In residential and commercial building areas, green roofs and green walls can be constructed to reduce the heat island effect. Besides, such construction can also retain rainwater, establish habitats for creatures, and provide green shield for citizens. [20]

Apart from establishing new greenway network that prioritizes sidewalk, we can also draw the lessons from "green cyber" of Tokyo. In other words, encouraging public transport such as subway to reduce private transport, and afforest these displaced elevated roads to form a three-dimensional green cyber. Some innovative urban infrastructure can also be installed in the "green cyber", such as solar energy utilization, hydrogen generation and surplus heat utilization facilities. In addition, some commercial facilities can be constructed around viaducts, and platform bridges can be built to link elevated roads with the second and third floors of surrounding buildings [11]. In the downtown of Hong Kong and Macao, the three-dimensional pedestrian system has been very mature. However, considering the limited space, we can even link and utilize the small space such as the continuous green space under street trees, corners of sidewalk, and road intersections to construct the green space system which is like a fiber network.

\section{Policy Support to High-density Cities’ Sustainable Development}

The land in high-density cities is very valuable, and the contradiction between land development and protection is significantly obvious. In particular, the developers and government departments in some Chinese regions often sacrifice green space for developing municipal facilities and various buildings. In essence, the selection relating to green space construction will become more intuitive if we quantize and monetize the value of green assets in a series of fields which have multiple potential benefits to expound on the whole benefits or site-related benefits . In this way, we can have a visualized economic selection at the beginning of developing the sustainable high-density cities.

In this aspect, we can use the GI valuation tools which developed in the Northwest Region of the UK (GI Valuation Toolkit Calculator) for reference [22-23] to evaluate the economic and social influence of the GI resources in the city. The GI Valuation Toolkit Calculator provides a simple way to estimate the investment income of green assets - whether it can make contributions to local economy directly or provide more non-economic benefits for society and environment. The Toolkit can be used to estimate the economic benefits in the following 11 aspects:

1) Climate Change Adaptation and Mitigation; 2) Water Management and Flood Alleviation; 3) Place \& Communities; 4) Health; 5) Land and Property Values; 6) Investment; 7) Labour Productivity; 8) Tourism; 9) Recreation; 10) Biodiversity; 11) Land Management 
In the practice process, the relevant parameters can be amended to be more consistent with the actual local conditions.

The sustainable GI in high-density cities also require relevant polices to guarantee efficient implementation. For instance, Singapore's riverside greenway links roads, beaches and the land to be developed under the urban light rail to form a greenway network across the island. In order to ensure connectivity, the government sets up a special work team composed of members from various land management and implementation departments to cooperate in formulating the principles of developing greenways within the jurisdiction. The Garden City Action Committee also directly participates in coordinately solving various contradictions, and its executive agency National Park Service directly takes charge of developing and maintaining the greenway system. [17] America makes GI plans mainly through design charrette and adopts cooperative planning and design methods to provide a discussion, consultation and brainstorming platform for stakeholders, professionals and the personnel in relevant fields. [11-12] Participants from different industries and communities have their own understanding of the problems and have profound emotions and perception of the cities and communities they are familiar with, but researchers don't have such emotions and perception. However, unprofessional participants lack professional knowledge, so it is necessary to provide professional training for participants before the charrette so as to deepen their understanding of research problems. After the charrette, it is also important to summarize and share the charrette results in order to expand its influence and educate the public.

\section{CONCLUSION}

GI is natural life support system, and the connectivity of its components is very important. At the same time, GI as an important strategy for sustainable urban development provides a strategic solution to relieving the contradictions of urban land use, economic and ecological development, cultural protection and urban expansion in high-density cities. By summarizing the application trend of the GI theory in foreign cities, this paper puts forward some principles for planning the urban space in high-density cities.

\section{ACKNOWLEDGEMENT}

This research was supported by the National Natural Science Foundation of China (No. 51278205).

\section{REFERENCES}

[1] Karen S W.: Growing with Green Infrastructure, (CPSI Heritage Conservancy, RLA 2003).

[2] Tom Turner: City as Landscape: A Post- Postmodern View of Design and Planning, ( Taylor\&Francis, London 1995).

[3] David Rudlin, Nicholas Falk, URBED: Building the 21st Century Home. The Sustainable Urban Neighbourhood,( Architectural Press, Oxford 1999)

[4] Susannah E. Gill, John F. Handley, A. Roland Ennos, et al. Characterising the urban environment of UK cities and towns - A template for landscape planning, Landscape and Urban Planning 87(2002), p. 210-222.

[5] Konstantinos Tzoulas, KaleviKorpela, Stephen Venn, et al.: Promoting ecosystem and human health in urban areas using Green Infrastructure - A literature review, Landscape and Urban Planning 81(2007), p. 167-178.

[6] Dr David Goode: Green Infrastructure Report to the Royal Commission on Environmental Pollution [EB/OL]. (2006). http://www.rcep.org.uk/reports/26-urban/documents/green-infrastr ucture-david-goode.pdf.

[7] Li Min and Gong Fangying: The Sustainable Approach to the Green Space Layout in Super High-Density Urban Environment: A Case Study of Macau Peninsula, Procedia Engeering 21(2011), p. 922-928.

[8] Benedict M. and McMahon E.: Green infrastructure: linking landscapes and communities (Washington, Covelo, London: Island Press, 2006).

[9] Lafortezza R, Davies C, Sanesi G, et al.: Green Infrastructure as a tool to support spatial planning in European urban region, iForest-Biogeosciences and Forestry 6(3)(2013), p. 102.

[10] Liu Juanjuan, Li Baofeng, Nancy Rottle, Ning Yunfei: Constructing Life Support System in Urbanized Area: A Case Study of Urban Green Infrastructure in Seattle, Chinese Landscape Architecture (3)(2012), p. 116-120, In Chinese.

[11] Department of Landscape Architecture, University of Washington, the Open Space Seattle 2100 Coalition. Open Space Seattle 2100 Envisioning Seattle's Green Infrastructure for the Next Century [EB/OL], http://www.asla.org/awards/2007/07winners/439_gftuw.html.

[12] Rottle N., Maryman B.: Envisioning Seattle's Green Future: Visions and Strategies from The Green Futures Charrette[R/OL], Seattle: Open Space Seattle 2100, [2006].http://depts.washington.edu/open2100/book/book.complete. pdf.

[13] Carol Kambites and Stephen Owen: Renewed prospects for green infrastructure planning in the UK, Planning Practice and Research (4)(2006), p. 483-496.

[14] ECOTEC. The economic benefits of Green Infrastructure: Developing key tests for evaluating the benefits of Green Infrastructure[EB/OL],

(2008).http://www.gos.gov.uk/497468/docs/276882/752847/GIDe velopingtests.

[15] M. A. Bowman, Ann O’M., \& Pagano: Terra incognita: Vacant land and urban strategies. Economics review (103) (Georgetown University Press, Washington, DC 2004).

[16] Pagano, M. A., \& Bowman, A. O. (2000): Vacant land in cities: An urban resource. The Brookings Institution Survey Series, (December), 1-9.

[17] ZHANG Tianjie, LI Ze: Multi-objective greenway network in high-density cities: the park connector network in Singapore, Urban planning (5)(2013), p. 67-73, In Chinese.

\begin{tabular}{l} 
[18] OHNO $\mathrm{H}$ Fabric theory, [EB/OL] \\
\hline
\end{tabular} http://www.fibercity2050.net/books-2012/FibercityTHEORY.pdf

[19] Wang Jing, Zeng Jian, Su Yi: Application of Sustainable Fibre Greenway in Compact Urban Planning: A Case Study on Ohno Hidetoshi's Concept Planning for Tokyo 2050, Urban Planning 
Forum(4)(2009), p. 72-77, In Chinese.

[20] Shen Qingji: Introduce and discuss on a guide to green infrastructure for Canadian municipalities, Urban Planning Forum (5)(2005), p. 102-107, In Chinese.

[21] Jiang Lining, Ying Jun, Xu Juntao. Research on Urban Stormwater Management Based on Green Infrastructure: A Case Study of New York City, USA, Journal of Chinese Urban Forestry (6)(2012), p. 59-62, In Chinese.
[22] Green Infrastructure Valuation Toolkit, [EB/OL], http://www.greeninfrastructurenw.co.uk/html/index.php?page=proj ects\&GreenInfrastructureValuationToolkit=true

[23] North West Regional Assembly, Wigan, UK. "The North West Plan: Submitted Draft Regional Spatial Strategy for the North West of England.” [EB/OL]. (2008) [2013-01-20]. http://www.knowsley.gov.uk/pdf/PG18_RegionalSpatialStrategy-f or-the-NorthWest.pdf. 